\title{
Thermally Remendable Polyurethane Network Cross-Linked via Reversible Diels-Alder Reaction
}

\author{
Elena Platonova ${ }^{1}$, Islam Chechenov ${ }^{1}$, Alexander Pavlov ${ }^{2}$, Vitaliy Solodilov 1,3, Egor Afanasyev ${ }^{4}$, \\ Alexey Shapagin 5 (D) and Alexander Polezhaev ${ }^{1, * \mathbb{D}}$
}

1 Laboratory of Functional Composite Materials, Bauman Moscow State Technical University, 2nd Baumanskaya str., 5/1, 105005 Moscow, Russia; E-O-Platonova@yandex.ru (E.P.); ch-islam@bk.ru (I.C.); vital-yo@ya.ru (V.S.)

2 Laboratory for Nuclear Magnetic Resonance, A.N. Nesmeyanov Institute of Organoelement Compounds, Vavilova str., 28, 119334 Moscow, Russia; pavlov@ineos.ac.ru

3 Laboratory of Reinforced Plastics, Semenov Institute of Chemical Physics, Russian Academy of Sciences, 119991 Moscow, Russia

4 Laboratory for Polymer Materials, A.N. Nesmeyanov Institute of Organoelement Compounds, Vavilova str., 28, 119334 Moscow, Russia; nambrot@yandex.ru

5 Laboratory of Structural and Morphological Investigations, Frumkin Institute of Physical Chemistry and Electrochemistry, Leninsky Prospect 31, bld.4, 119071 Moscow, Russia; shapagin@mail.ru

* Correspondence: avp@emtc.ru

check for updates

Citation: Platonova, E.; Chechenov, I.; Pavlov, A.; Solodilov, V.; Afanasyev, E.; Shapagin, A.; Polezhaev, A. Thermally Remendable Polyurethane Network Cross-Linked via Reversible Diels-Alder Reaction. Polymers 2021, 13, 1935. https://doi.org/10.3390/ polym13121935

Academic Editors: Joost Brancart, Sandra Schlögl and Sophie Norvez

Received: 15 May 2021

Accepted: 6 June 2021

Published: 10 June 2021

Publisher's Note: MDPI stays neutral with regard to jurisdictional claims in published maps and institutional affiliations.

Copyright: (c) 2021 by the authors. Licensee MDPI, Basel, Switzerland. This article is an open access article distributed under the terms and conditions of the Creative Commons Attribution (CC BY) license (https:// creativecommons.org/licenses/by/ $4.0 /)$

\begin{abstract}
We prepared a series of thermally remendable and recyclable polyurethanes crosslinked via reversible furan-maleimide Diels-Alder reaction based on TDI end-caped branched Voranol 3138 terminated with difurfurylamine and 4, $4^{\prime}$-bis(maleimido)diphenylmethane (BMI). We showed that Young modulus strongly depends on BMI content (from 8 to $250 \mathrm{MPa}$ ) that allows us to obtain materials of different elasticity as simple as varying BMI content. The ability of DA and retro-DA reactions between furan and maleimide to reversibly bind material components was investigated by NMR spectroscopy, differential scanning calorimetry, and recycle testing. All polymers obtained demonstrated high strengths and could be recovering without significant loss in mechanical properties for at least five reprocessing cycles.
\end{abstract}

Keywords: polyurethanes; Diels-Alder reaction; crosslinked polyurethanes; recyclability

\section{Introduction}

Global polyurethane production is more than 22 million tons (for PU foams), and most of this production will not be recycled [1,2]. The synthetic design of recyclable materials is essential for sustainability, and there is a noticeable growth in the number of papers in the field in the last decade [1]. There are two ways to increase polyurethane sustainability: developing materials based on biorenewable sources such as lignin or sugars [3-6] and developing recycling technologies $[7,8]$. Generally, PU may be recycled by either destructive or nondestructive methods. Linear polyurethanes can be reprocessed through conventional molding processes like other thermoplastics [9-12]. However, the polyurethane polymer family is not limited to thermoplastics, but there are many crosslinked formulations required for high solvent resistance [13,14], high strength [15,16], and abrasion resistance [17]. Crosslinked polymers cannot be reshaped or repaired and finally recycled when damaged once a crosslinked network is formed $[10,18]$. There are several approaches to commercial crosslinked PUs recycling: advanced chemical and thermochemical recycling, mechanical recycling, energy recovery, and product recycling, but all of them suffer from inefficiency and high cost $[1,10]$.

The introduction of covalent bonds, which can reversibly dissociate upon extrinsic stimuli, allows to obtain mendable crosslinked materials [19] and could substantially simplify material recycling [20-23]. Reversible Diels-Alder reaction between furan and 
maleimide is one of the most sustainable approaches to remendable materials development [24] with the advantage of inexpensive biomass-derived furans [25-27] and commercially available bismalemide crosslinkers as main components. A technological thermal window required for processing is usually around $\mathrm{rt}-70{ }^{\circ} \mathrm{C}$ for bonding and $100-140{ }^{\circ} \mathrm{C}$ for the reversed process [28]. This approach is also widely used for the development of self-healing polymer systems $[29,30]$. It is also essential for sustainability to increase the number of carbon atoms derived from renewable sources. Furans, maleimides [31], and polyols [11,32-34] are bioderived and therefore are ideal candidates for this purpose. Our previous work [31] presented linear thermally remendable PUs extended via reversible DAreaction that demonstrated excellent self-healing ability. Several reports showed [35-37] that branched PUs have enhanced mechanics and self-healing properties than their linear counterparts. For example, Du et al. achieved crosslinked material by reaction between secondary amino-groups of furylamine-functionalized prepolymer and isocyanate groups of 4,4-diphenylmethane diisocyanate-functionalized preform at elevated temperature [35]. Later the same authors used branched triol as a chain extender for branched PU synthesis [36]. Here we decided to increase a soft segment molecular mass compared to $M=1000$ in Du at all. [35,36]), as far as elongation of the soft segment in remendable PUs to achieve a positive influence on polymer chains mobility and consequently enhances self-healing properties and potential recyclability [38].

We designed netlike remendable PU using branched glycerine-based propylene oxide and ethylene oxide block-copolymer, Voranol 3138, as the soft segment. Previously polyols of such or similar structures were used for foams [39,40] and amphiphilic materials [41] fabrication, but not for self-healing or mendable polymers. A new furan-rich component difurfurylamine, synthesized from furfural, was applied for increasing local furan content and speeding up DA-adduct formation compared to the know systems based on furfuryl alcohol or furfurylamine. We choose commercially available methylenedi-1,4phenylene)bismaleimide (BMI) as a crosslinker. It is worthwhile to say that a significant advantage of the furan-terminated prepolymer is its longer shelf-life and moisture insensitiveness compared to its regular isocyanate-terminated counterparts [42].

\section{Materials and Methods}

\subsection{Materials}

TDI (toluene-2,4-diisocyanate, 80\%), sodium borohydride (98\%), BMI (1,10-(methylenedi1,4-phenylene)bismaleimide, 95\%), and BHT (2,6-di-tert-butyl-4-methylphenol, 99.0\%) were purchased from Aldrich and used as received. Voranol $3138\left(\mathrm{M}_{\mathrm{n}}=3000\right)$ was purchased from Dow Europe $\mathrm{GmbH}$ and dried under vacuum at $110{ }^{\circ} \mathrm{C}$ prior to use. Hydrofuramide was prepared using a published procedure [43] from furfural and ammonia. DMF (N,Ndimethylformamide) was purchased from Acros dried over $\mathrm{CaH}_{2}$, and distilled prior to use.

\subsection{Synthesis of Difurfurylamine}

Difurfurylamine was prepared by a modified literature procedure [31] (Scheme 1). Hydrofuramide ( $50 \mathrm{~g}, 0.19 \mathrm{~mol})$ was gradually added to the ice-cold suspension of sodium borohydride (excess) in methanol. The reaction mixture was stirred for an additional $0.5 \mathrm{~h}$ after complete hydrofuramide dissolution and then diluted with water to $1 \mathrm{~L}$ and extracted with $\mathrm{CH}_{2} \mathrm{Cl}_{2}$. The organic layer was washed with water and brine and dried with $\mathrm{Na}_{2} \mathrm{SO}_{4}$. Volatiles were removed by rotary evaporation, and the resulting crude product was distilled in vacuo $\left(130^{\circ} \mathrm{C} / 16-18 \mathrm{mbar}\right)$ to obtain almost colorless liquid $(27.2 \mathrm{~g}, 55 \%)$. 


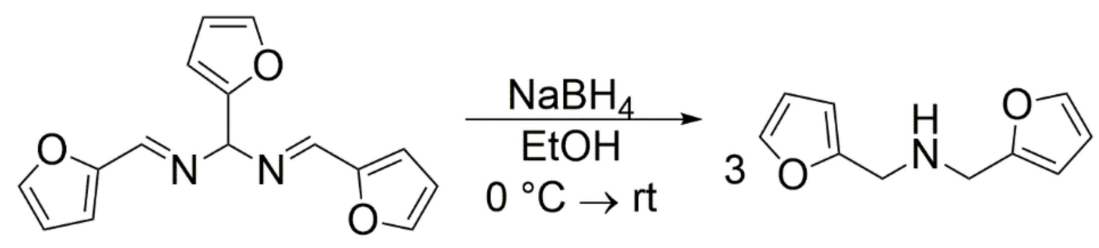

Scheme 1. Synthesis of difurfurylamine.

\subsection{Synthesis of PU-V0}

Prepolymer PU-V0 was prepared using conventional two-step method. At the first step TDI (2.3 g, $13.4 \mathrm{mmol})$ reacted with Voranol $3138(12.5 \mathrm{~g}$, $4.2 \mathrm{mmol})$ in a $100 \mathrm{~mL}$ two-necked round bottom flask, equipped with magnetic stirrer and dropping funnel. The reaction was carried out at $60^{\circ} \mathrm{C}$ under an argon atmosphere for $3 \mathrm{~h}$. The reaction progress was monitored with IR-spectroscopy. At the second step, the reaction mixture was cooled to room temperature, diluted with DMF $(3 \mathrm{~mL})$, and difurfuryl amine $(2.3 \mathrm{~g}, 13.0 \mathrm{mmol})$ dissolved in DMF ( $3 \mathrm{~mL}$ ) was added dropwise into the isocyanate end-capped prepolymer solution in about $15 \mathrm{~min}$. Reaction mixture was stirred at $60^{\circ} \mathrm{C}$ under an argon atmosphere for $12 \mathrm{~h}$. Yield: 21.0 g. ${ }^{1} \mathrm{H}$ NMR (400 MHz, DMSO- $\left.d_{6}, \delta\right): 9.52$ (s, 3H, -NH-CO-O-), 8.05 $\left(\mathrm{d}, \mathrm{J}_{\mathrm{HH}}=9.8 \mathrm{~Hz}, 3 \mathrm{H},-\mathrm{HNC}(\mathrm{O}) \mathrm{NH}-\mathrm{Ar}\right), 7.61\left(\mathrm{~d}, J_{\mathrm{HH}}=6.9 \mathrm{~Hz}, 3 \mathrm{H},=\mathrm{CHO}-\right.$ of furan ring $)$, $7.44\left(\mathrm{~d}, J_{H H}=6.4 \mathrm{~Hz}, 3 \mathrm{H},-\mathrm{Ar}\right), 7.26-7.12(\mathrm{~m}, 3 \mathrm{H},-\mathrm{Ar}), 7.04\left(\mathrm{~d}, J_{H H}=5.3 \mathrm{~Hz}, 3 \mathrm{H},-\mathrm{Ar}\right)$, $6.41(\mathrm{~s}, 6 \mathrm{H},=\mathrm{CH}-\mathrm{CH}=$ of the furan ring), $6.32(\mathrm{~s}, 6 \mathrm{H},=\mathrm{CH}-\mathrm{CH}=$ of the furan ring), $4.54(\mathrm{~s}$, $\left.12 \mathrm{H},-\mathrm{N}-\mathrm{CH}_{2}-\right), 3.71-3.62\left(\mathrm{~m}, 5 \mathrm{H},-\mathrm{O}-\mathrm{CH}_{2}-\mathrm{CH}(\mathrm{O})-\mathrm{CH}_{2} \mathrm{O}-\right), 3.57-3.39\left(\mathrm{~m}, 112 \mathrm{H},-\mathrm{CH}_{2}-\right.$ of polypropylene oxide and polyethylene oxide), $3.35-3.17\left(\mathrm{~m}, 66 \mathrm{H},-\mathrm{CH}_{2}-\mathrm{CH}\left(\mathrm{CH}_{3}\right)-\mathrm{O}-\right)$, $1.20\left(\mathrm{~s}, 9 \mathrm{H}, \mathrm{CH}_{3}-\mathrm{Ar}\right), 1.04\left(\mathrm{~d}, \mathrm{~J}_{\mathrm{HH}}=5.0 \mathrm{~Hz},-\mathrm{O}-\mathrm{CH}\left(\mathrm{CH}_{3}\right)-\mathrm{CH}_{2}-\right) ;{ }^{13} \mathrm{C} \mathrm{NMR}(101 \mathrm{MHz}$, DMSO- $\left.d_{6}, \delta\right): 155.58,153.68$ 151.91, $143.1138 .37,138.23,130.32,123.13,118.05,110.93$, 108.59, 75.04, 72.71, 42.81, 17.43; IR (ATR, neat, $\mathrm{cm}^{-1}$ ): 3315, 2971, 2931, 2895, 2897, 1728, $1672,1600,1531,1506,1453,1374,1343,1296,1225,1103,1012,924,868,816,737$.

Details on material characterization can be found in the Supplementary Materials.

\subsection{Synthesis of Crosslinked PUs}

PU-V1.0. BMI (0.93 g, $2.5 \mathrm{mmol})$ and BHT $(0.0057 \mathrm{~g}, 0.05 \mathrm{mmol}, 1 \% \mathrm{~mol}$ to the amount of prepolymer and crosslinker) as stabilizer were added to $\mathrm{Fu}_{2} \mathrm{~N}$-prepolymer PU-V0 (7.0 g, $1.7 \mathrm{mmol}$ ) in $6 \mathrm{~mL}$ DMF. The reaction mixture was heated to $60^{\circ} \mathrm{C}$ for $3 \mathrm{~h}$, then carried onto a glass surface and cured in an oven for $48 \mathrm{~h}$ to afford semitransparent polymer film. Polyurethanes with different prepolymer:BMI ratios (PU-V2.0 and PU-V3.0) were synthesized using the same protocol.

Details on material characterization can be found in the Supplementary Materials.

\subsection{Film Preparation}

Polymer solution in DMF $\left(0.12 \mathrm{~g} \mathrm{~mL}^{-1}\right)$ was heated to $60^{\circ} \mathrm{C}$, poured into a glass Petri dish, and kept in an oven at $60^{\circ} \mathrm{C}$ for $48 \mathrm{~h}$. All films were stored at room temperature not more than a week before testing.

\subsection{Recycling of PU-V1.0-3.0}

A $50 \mathrm{~mL}$ of DMF was added to $10 \mathrm{~g}$ of cut polymeric material, and a mixture was heated to $100{ }^{\circ} \mathrm{C}$ while stirring until complete dissolution. The hot solution was poured into PTFE form and cured at $60^{\circ} \mathrm{C}$ for $48 \mathrm{~h}$.

\subsection{Characterization}

NMR spectra were recorded by a Bruker Avance 600 NMR Spectrometer (600.1 MHz), residual proton signal of deuterated solvent was used as reference. ATR-FTIR was performed by Nicolet iS10 spectrometer in the range of 4000 to $600 \mathrm{~cm}^{-1}$ on a germanium crystal. Thermogravimetric analysis (TGA) was performed by Netzsch TG 209 F1 Libra within a temperature range of $30-550{ }^{\circ} \mathrm{C}$ at a heating/cooling rate of $10 \mathrm{~K} \mathrm{~min}^{-1}$ under an argon atmosphere. Differential scanning calorimetry (DSC) was performed by a Netzsch 
DSC 204 F1 Phoenix within a temperature range of $-80-300{ }^{\circ} \mathrm{C}$ at heating/cooling rates of $10 \mathrm{~K} \mathrm{~min}^{-1}$ (-80-160 ${ }^{\circ} \mathrm{C}$ at heating/cooling rates of $5 \mathrm{~K} \mathrm{~min}^{-1}$ for $\mathrm{T}_{\mathrm{g}}$ determination) under an argon atmosphere. A sample weight of about $20 \mathrm{mg}$ was used for each measurement. Thermal analysis was performed by TA Instruments TMA Q400E in the penetration mode. Specimens of $0.6 \mathrm{~cm}$ diameter were tested within a temperature range of $-70-390{ }^{\circ} \mathrm{C}$ at heating/cooling rates of $5^{\circ} \mathrm{C} \mathrm{min}^{-1}$, at the load of $1 \mathrm{~N}$, and penetration probe diameter of $2.54 \mathrm{~mm}$. Transmission electron microscopy was performed by a Philips TEM-301. Samples for TEM were prepared using the replica technique. Cryo-fractured surfaces were obtained in liquid nitrogen. Samples phase structure was identified by oxygen plasma etching in 40 min on Edwards E306A evaporator. Mechanical properties $\left(\sigma_{t}, E, \varepsilon, \sigma_{t}(\varepsilon)\right.$ were determined from the uniaxial tensile strength test. Dogbone-shaped samples were cut from film using a special blade (length $15 \mathrm{~mm}$, width $2 \mathrm{~mm}$, see Figure S12 and Table S1 in the Supplementary Materials) and hand press. Film thickness was from 1.5 to $2.0 \mathrm{~mm}$. The samples were stretched on a Zwick Roell Z100 universal testing machine at a $150 \mathrm{~mm} / \mathrm{min}$ loading speed. An applied load $P$ and a strain $\varepsilon$ were recorded as loading diagrams. Further, the stress at break $\sigma_{t}$, the elongation $\varepsilon$, and the elastic modulus $E$ were calculated from the diagrams.

\section{Results and Discussion}

\subsection{Synthesis and Characterization of PU-V0 and PU-V1.0-3.0}

Thermally remendable PUs containing difuran moieties were prepared by a two-step polymerization process and were characterized by FTIR and ${ }^{1} \mathrm{H}-\mathrm{NMR}$ spectra (Scheme 2) using the same protocol we previously designed [31,44]. Briefly, Voranol 3138 reacted with $3 \mathrm{~mol}$ of TDI at $60^{\circ} \mathrm{C}$ and then terminated with difurfurylamine resulted in transparent viscous liquid (PU-V0). Reaction progress was monitored with ATR-IR, and the disappearance of the isocyanate band at $2265 \mathrm{~cm}^{-1}$ indicated completion of the reaction between difurfurylamine and isocyanate [45]. A sample of PU-V0 and BMI in different molar ratios (1:1.5 for PU-V1.0, 1:2 for PU-V2.0, and 1:2.5 for PU-V3.0) were dissolved in DMF, cast in glass, or PTFE mold, and heated at $60^{\circ} \mathrm{C}$ for $48 \mathrm{~h}$ in the oven yielded elastic yellow, semitransparent films. BHT $(1 \% \mathrm{~mol})$ was added to a solution to prevent maleimide polymerization. When less than 1.5 eq. of BMI was used, the curing was incomplete, and the film formed was sticky and not suitable for testing. An excess of unreacted BMI crystallizes on the film surface when more than 2.5 eq. of BMI has been used.

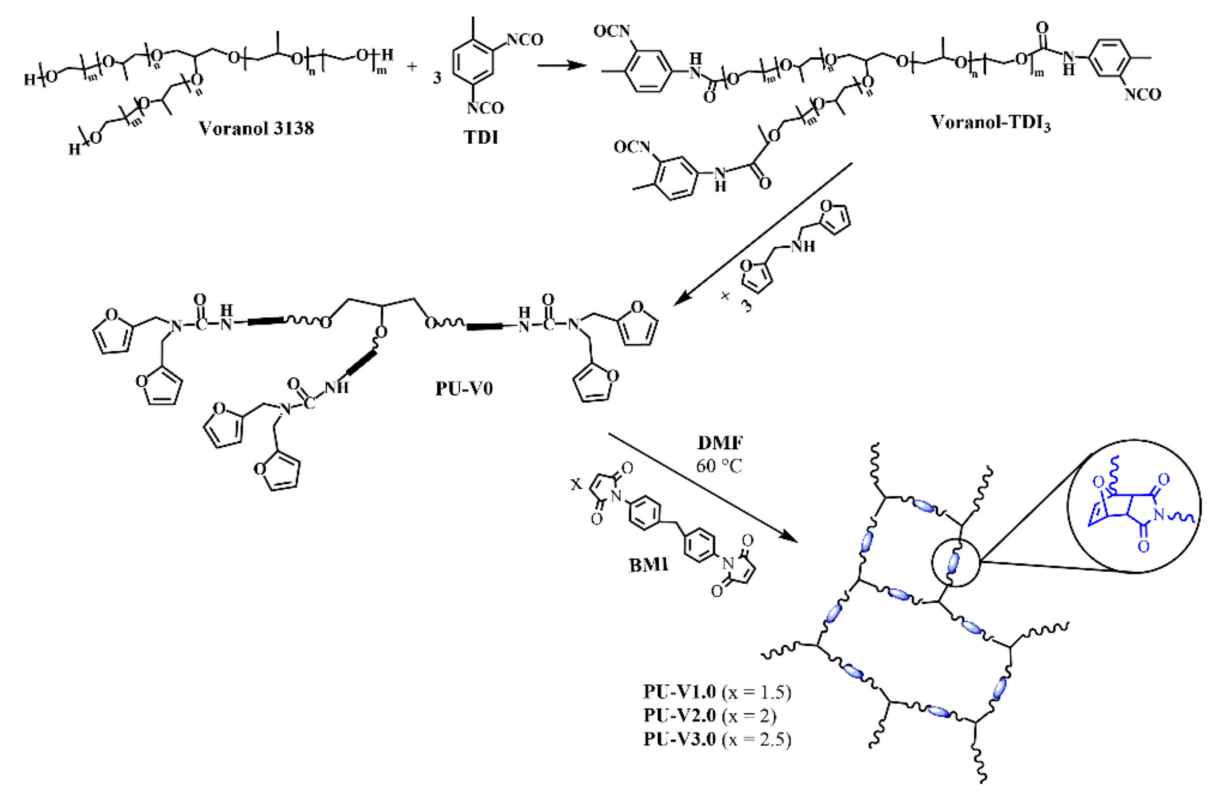

Scheme 2. Synthesis of PU-V0 and PU-V1.0-3.0. 
The FTIR spectra of the furan-terminated oligomer PU-V0, BMI, and films of crosslinked PU-V1.0-3.0 are shown in Figure 1. A decreasing of the band at $741 \mathrm{~cm}^{-1}$ associated with furan ring and appearance of the weak band at $1776 \mathrm{~cm}^{-1}$ characteristic to a furan-maleimide Diels-Alder adduct in the spectra of polymers PU-V1.0-3.0 confirmed DA-adduct formation $[46,47]$. However, the presence of two $C=O$ bands stretches at $1707 \mathrm{~cm}^{-1}$ may be assigned to partially unreacted maleimide groups. We speculate that incomplete behavior of the DA-reaction between prepolymer and BMI may be caused by increasing viscosity. Continuous heating of the sample did not change spectra, meaning that a higher conversion of the starting material cannot be obtained with prolonged heating. That means increasing furan content in the preform structure is essential to obtained higher crosslink density.

All polymers obtained (PU-V1.0-3.0) were not soluble in DMSO at r.t. and no leakage of BMI was detected with NMR after $12 \mathrm{~h}$ soaking of polymer in DMSO-d ${ }^{6}$ in NMR tube compared to PPG2000-based polymers that were perfectly soluble in DMSO. Prolonged heating at $100{ }^{\circ} \mathrm{C}$ was necessary to obtain a homogeneous solution required for ${ }^{1} \mathrm{H}-\mathrm{NMR}$ spectra registration. We believe that at least a partial $\mathrm{rDA}$ reaction occurred during this process (Figure 2). The ${ }^{1} \mathrm{H}-\mathrm{NMR}$ spectra of preheated samples showed residual furan ring signals at 7.62, 6.42, and $6.32 \mathrm{ppm}$, and at the same time, a new signal of DA adduct vinyl protons appeared at 6.52-6.26 ppm. All three polymers' proton NMR spectra contained signals from a crosslinking agent, which may be the result of DA-bonds cleavage caused by heating upon specimen preparation. The multiplet at $4.87 \mathrm{ppm}$ corresponded to protons of $\mathrm{N}-\mathrm{C}(\mathrm{O})-\mathrm{O}-\mathrm{CH}_{2}$-fragment [41].

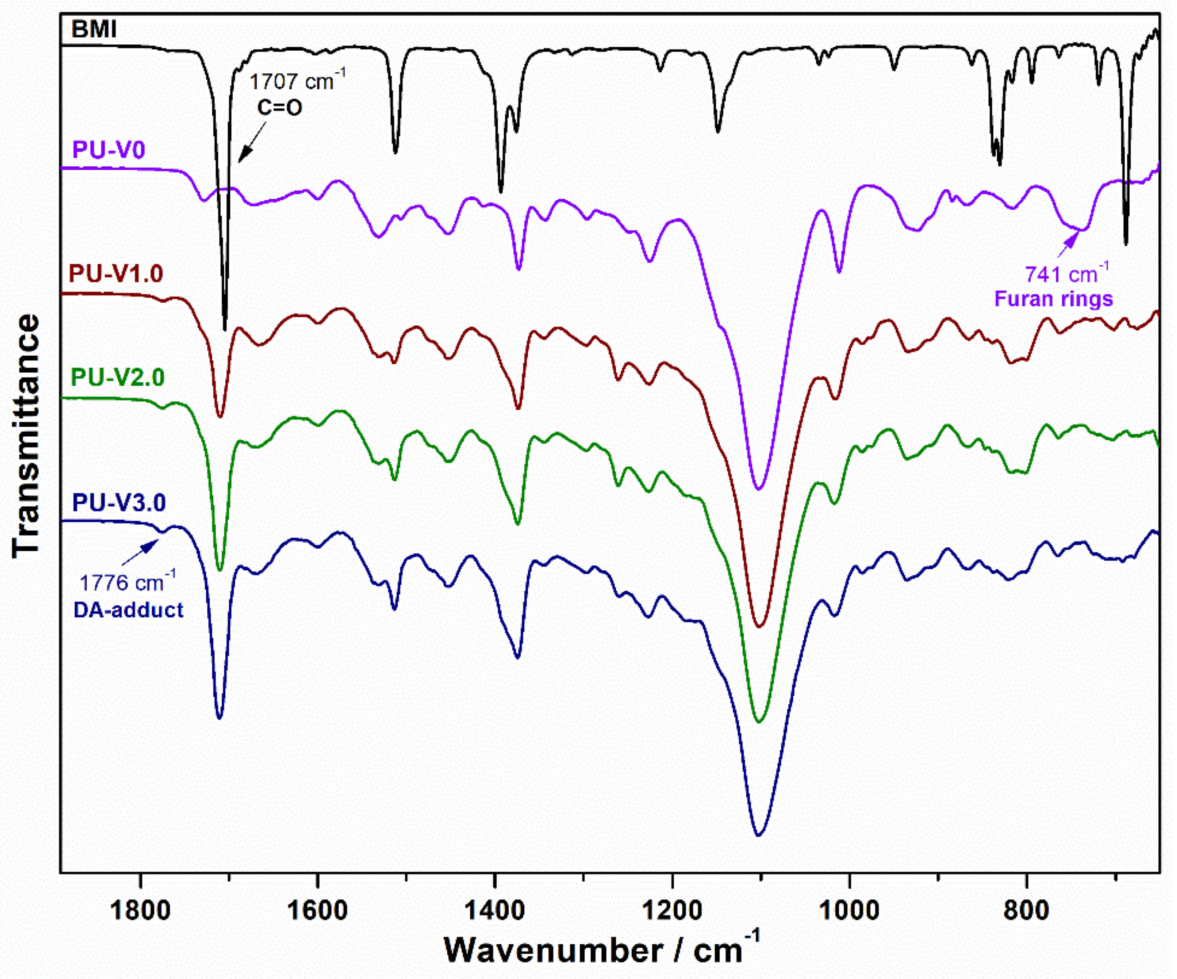

Figure 1. ATR-FTIR spectra of PU-V0 and PU-V1.0-3.0.

Soaking $6 \mathrm{~g}$ of the PU-V3.0 in $20 \mathrm{~mL}$ of DMF for $12 \mathrm{~h}$ leaded to swelling and consumption of all DMF used. Washing of the specimen with more DMF and analysis of a soluble fraction showed $<10 \%$ of the mass leached to DMF mostly consisted of BMI. The above results indicate that the crosslinked PUs were successfully obtained in the mold and prolonged heating over $100{ }^{\circ} \mathrm{C}$ in a polar solvent is required to break the network.

In our previous study, we presented linear remendable PU with good processability and solubility in DMF (even at $60^{\circ} \mathrm{C}$ ) [31]. By contrast with linear PUs netlike PU-V1.03.0 were almost insoluble in common organic solvents (DMF, DMSO, acetone) at room 
temperature and swelled in a solvent with gel formation. Only by heating those gels to the rDA temperature $>\left(100^{\circ} \mathrm{C}\right)$ we obtained homogeneous solutions.

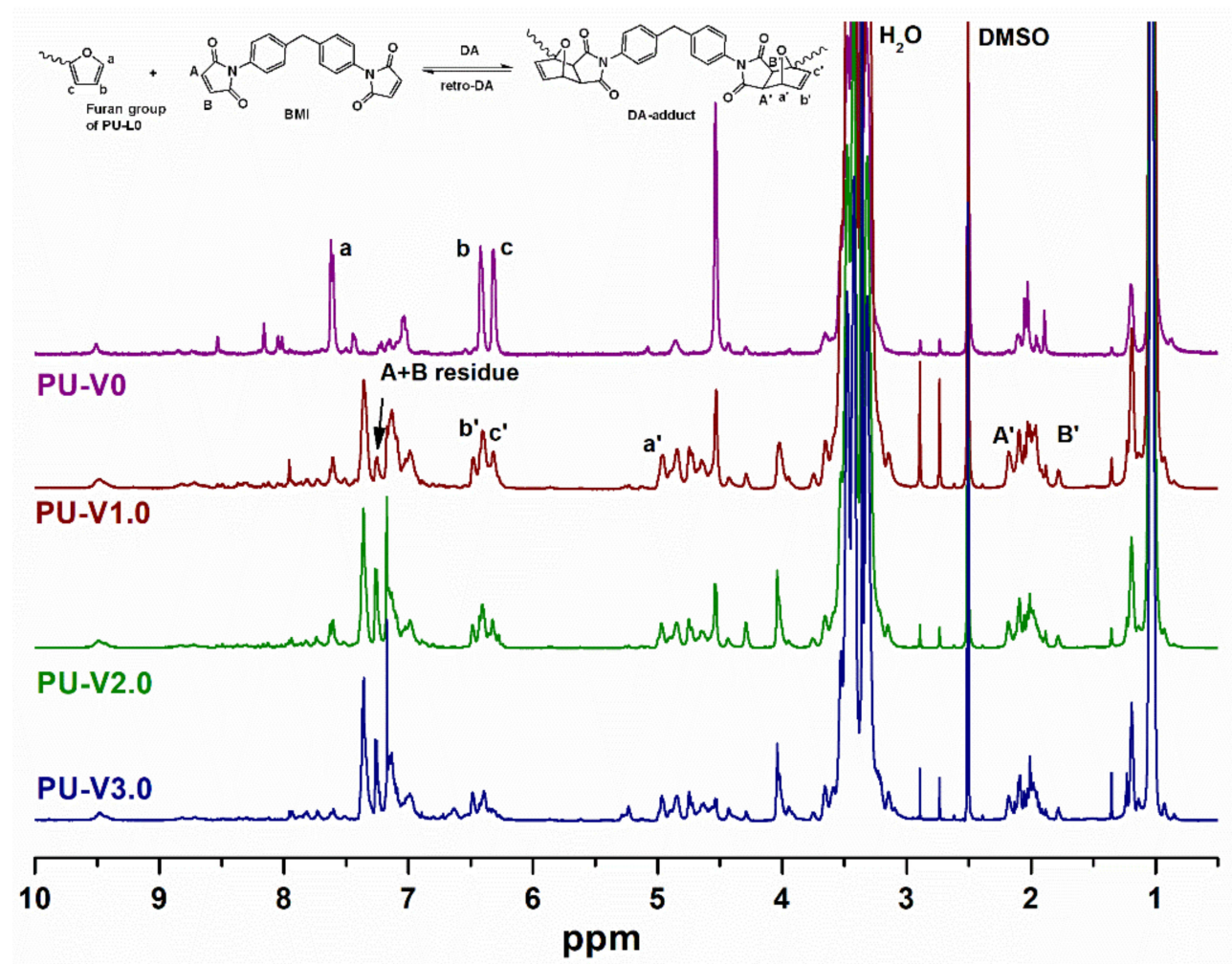

Figure 2. ${ }^{1} \mathrm{H}$ NMR spectra of PU-V0 and PU-V1.0-3.0.

\subsection{Thermal Properties and Reversibility of the DA Bonds}

The thermal stability of PU-V1.0-3.0 was investigated with TGA under an argon atmosphere (Figure 3a). The temperature values at 5\% mass loss (T5\%) were 267, 279, and $285^{\circ} \mathrm{C}$ for PU-V1.0-3.0, respectively. All polymer samples showed a slow weight loss in the range of $260-360{ }^{\circ} \mathrm{C}(19.0 \%, 21.8 \%$, and $21.3 \%$ for PU-V1.0-3.0, respectively), suggesting their high thermal stability. Main weight loss occurs in the range of $370-450{ }^{\circ} \mathrm{C}(85.9 \%$, 83.2\%, and 75.0\% for PU-V1.0-3.0, respectively). Both PU-V2.0 and PU-DA3.0 exhibited a slightly higher amount of char residue (16.8 and $25.0 \%$, respectively) compared to PU-V1.0 (14.1\%). We assume that DA-adducts decomposed to initial components via rDA-reaction and thermal stability of BMI and its degradation products was higher than those of furylpolyurethanes [48] that explains higher chair residue. A similar tendency was observed for the previously synthesized linear PUs: samples with higher BMI content revealed higher char residue [31]. DTG curves of PU-V1.0-3.0 (Figure 3b) also had maximums within the range of $295-310{ }^{\circ} \mathrm{C}$ associated with weight loss derived from the thermal decomposition of the furan-containing prepolymer. Small peaks at about $160{ }^{\circ} \mathrm{C}$ may be caused by evaporation of DMF traces in the material. The main thermal parameters of the pristine PU-V1.0-3.0 are listed in Table 1. TGA curves for pristine and recycled samples were very similar, proving that recycling does not affect the thermal properties of polymers. 


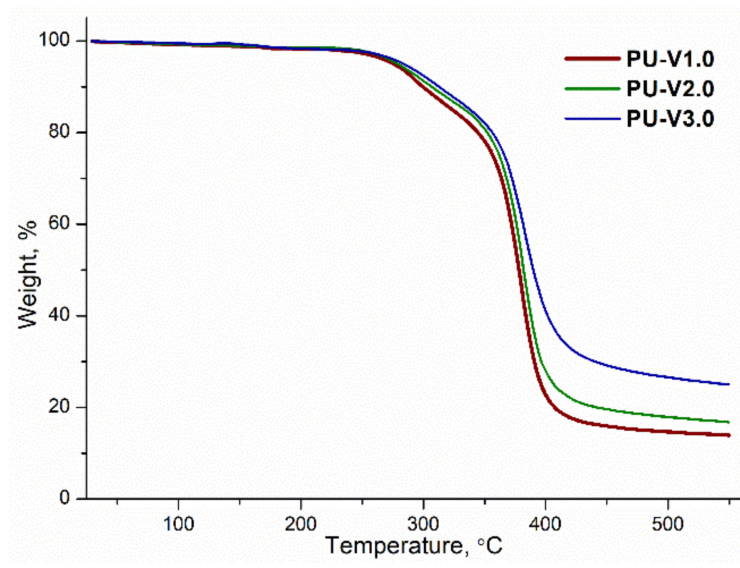

(a)

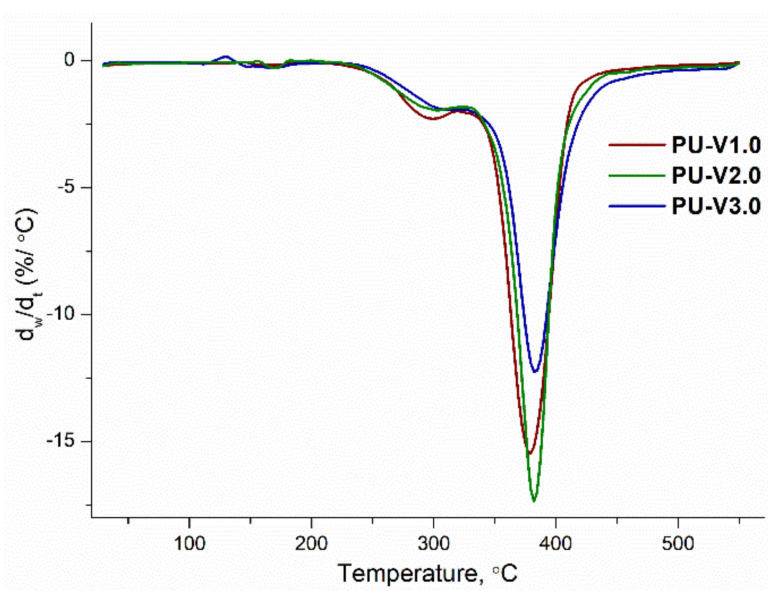

(b)

Figure 3. Thermogravimetric analysis (TGA) curves (a) and DTG curves (b) of PU-V1.0-3.0.

Table 1. Thermal parameters of the PU-V1.0-3.0 ${ }^{1}$.

\begin{tabular}{ccccc}
\hline Sample & $\mathbf{T}_{\mathbf{d} 5 \%}$ & $\mathbf{T}_{\mathbf{d 1 0} \%}$ & $\mathbf{T}_{\mathbf{d m a x}}$ & Residue (wt\%) \\
\hline PU-V1.0 & 267 & 300 & 380 & 14.1 \\
PU-V2.0 & 279 & 307 & 382 & 16.8 \\
PU-V3.0 & 285 & 330 & 383 & 25.0 \\
\hline
\end{tabular}

${ }^{1} \mathrm{Td} 5 \%$ : the initial decomposition temperature at $5 \mathrm{wt} \%$ loss of the original weight. $\mathrm{T}_{\mathrm{dmax}}$ : the temperature at the maximum degradation rate.

Thermal properties and DA-bonds reversibility of PU-V1.0-3.0 were investigated by DSC (Figure 4). The first heating curves (solid line) of all three polymers demonstrated two endothermic peaks: at 88 and $131{ }^{\circ} \mathrm{C}$ for PU-V1.0, 84 and $130{ }^{\circ} \mathrm{C}$ for PU-V2.0 and 74 and $130^{\circ} \mathrm{C}$ for PU-V3.0 assigned to rDA cleavage of endo and exo isomers, respectively [49]. Endo-adduct as the kinetically favored product has lower rDA-reaction temperature while exo-adducts as thermodynamically-favored products are frequently significantly thermally stable and have higher rDA-reaction temperature [49,50]. DSC-curves of branched PUs were similar to DSC-curves of linear PUs, reported previously: thermograms had two endothermic peaks as well, and the rDA peak temperatures of $115-131^{\circ} \mathrm{C}$ for branched materials were not very far from rDA peak temperatures of $124-136^{\circ} \mathrm{C}$ for linear PPG2000-based PUs [31].

Retro Diels-Alder reaction peak was not observed on the second heating curves for all polymer samples (Figure 4, dash lines) that agrees with the complete cleavage of DAadducts. We also measured $\mathrm{Tg}$ values of a soft segment for all the polymeric materials obtained $\left(-54.7^{\circ} \mathrm{C},-53.3^{\circ} \mathrm{C}\right.$, and $-50.4^{\circ} \mathrm{C}$ for PU-V1.0-V3.0, respectively, Figures S9-S11 in the Supplementary Materials). We suggest that a slight increase in Tg associated with higher BMI content was due to an increase in overall rigidity and density of the network.

We carried out DSC analysis to demonstrate the DA-bonds formation reversibility after several reprocessing runs using a sample of PU-V3.0 as a representative example (Figure 5). The first heat curves (solid) of all recycled polymer samples (from PU-V3.0 to PU-V3.5) demonstrated rDA-reaction peaks $\left(64-73{ }^{\circ} \mathrm{C}\right.$ for endo and $115-131{ }^{\circ} \mathrm{C}$ for exo isomer cleavage, respectively), shows successful DA-crosslinks formation after every recycles. Retro DA reaction peak was not observed on the second heating curves for all polymer samples (Figure 5, dash lines). All DSC curves for the pristine and recycled sample of PU-V3.0 were similar in shape and the rDA-peaks were reproduced in a quality manner. 


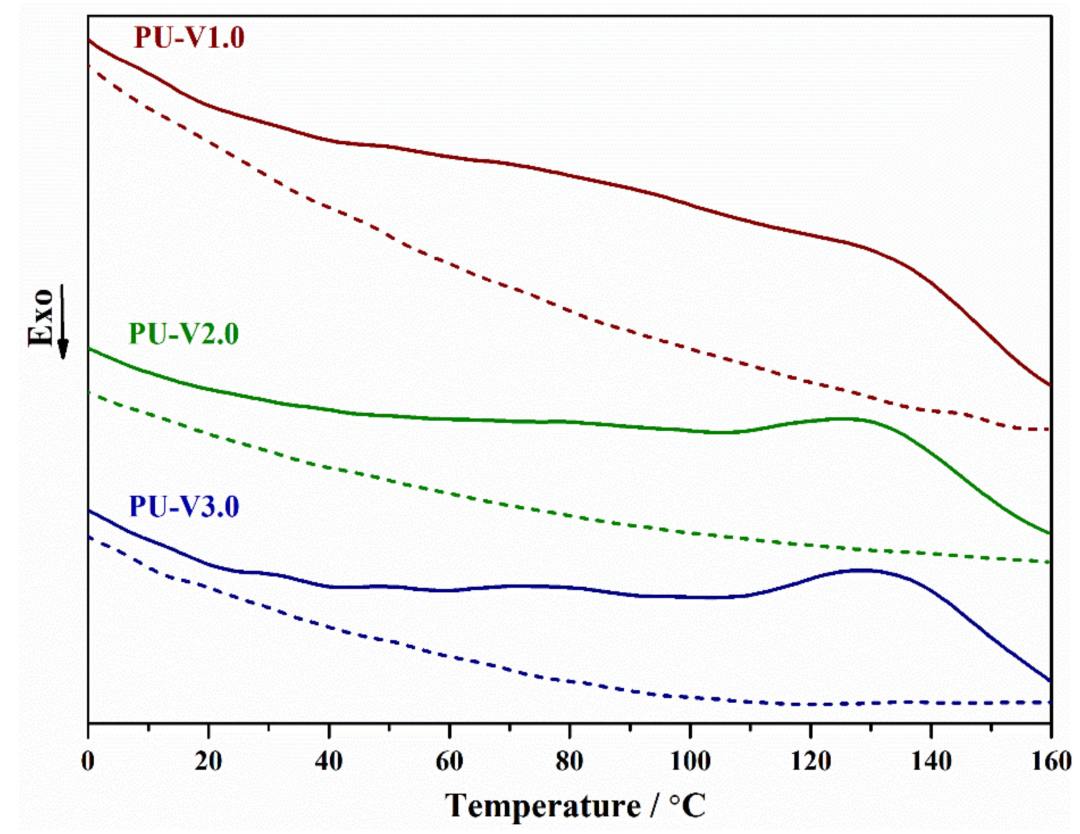

Figure 4. DSC curves of PU-V1.0-3.0 (solid lines—first heat; dash lines—second heat).

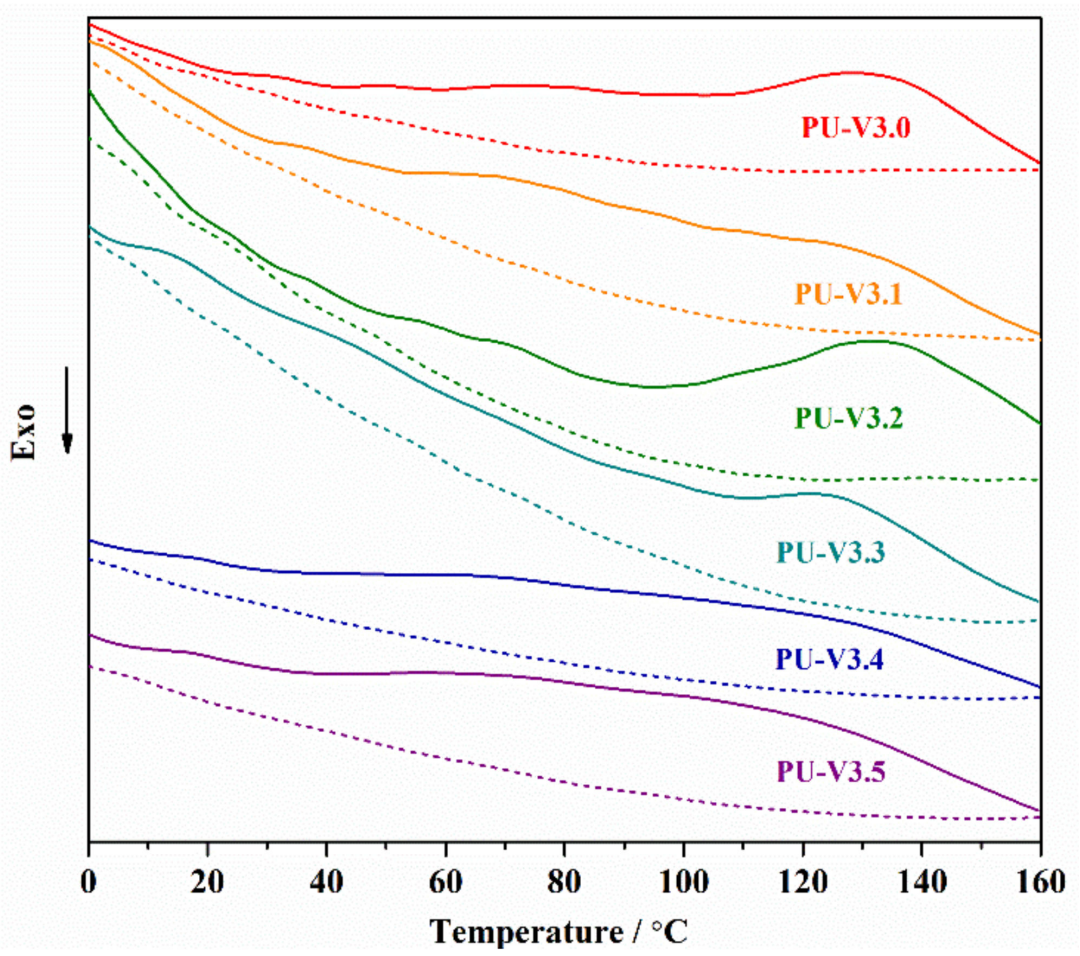

Figure 5. DSC curves of PU-V3.0-3.5 (solid lines—first heat; dash lines—second heat).

We also tested all polyurethane samples in the TMA experiment (Figure 6). Thermomechanical analysis in penetration mode was performed for additional investigation of the thermomechanical properties of the obtained materials. 


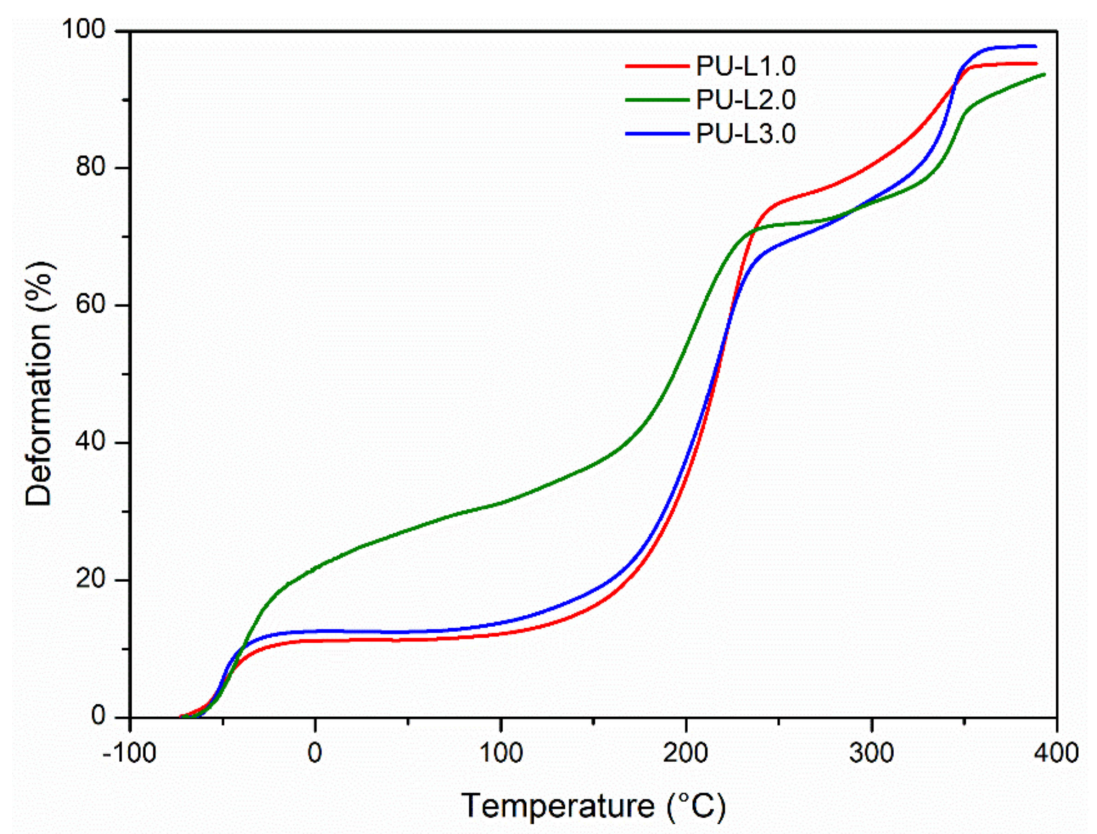

Figure 6. TMA curves of PU-V1.0-3.0.

The first transition near $-55{ }^{\circ} \mathrm{C}$ refers to the soft segment glass transition. The second one $\left(175-184^{\circ} \mathrm{C}\right)$ is the result of the rDA-reaction and dissociation of hard segment hydrogen bonds [51]. The third transition at temperatures higher than $310^{\circ} \mathrm{C}$ corresponds to the thermal destruction additionally confirmed with TGA data.

\subsection{Mechanical Properties and Recycling Tests}

Typical loading diagrams for the studied polymers showed that the deformation of polyurethanes depends on the prepolymer/BMI ratio and samples with higher BMI content demonstrated higher Young modulus (Figure 7 and Figures S13-S17 in the Supplementary Materials). For PU-V1.0 and PU-V2.0, the samples first deform elastically, i.e., the stress in the material is directly proportional to elongation. With further loading, the materials begin to deform irreversibly and collapse at approximately the same final elongation for both ratios. For polymer with higher BMI content (PU-V3.0) a deformation also starts from the elastic section. Furthermore, a region with small load changes with a noticeable increase in elongation appeared on a curve. This section corresponds to the fluidity of the material. With a further rise in strain for this sample, stress increased due to the orientational hardening of the composition. Moreover, the elongation at break is 50\% higher for PU-V3.0 than for materials with a lower prepolymer/BMI ratio. Loading diagrams also show a gentler slope of a linear part of the curve for compositions with lower BMI content.

The difference between diagrams agrees with the higher degree of crosslinking associated with increased BMI content. A denser network results in higher modulus, tensile strength, as well as twice bigger elongation at the break. 


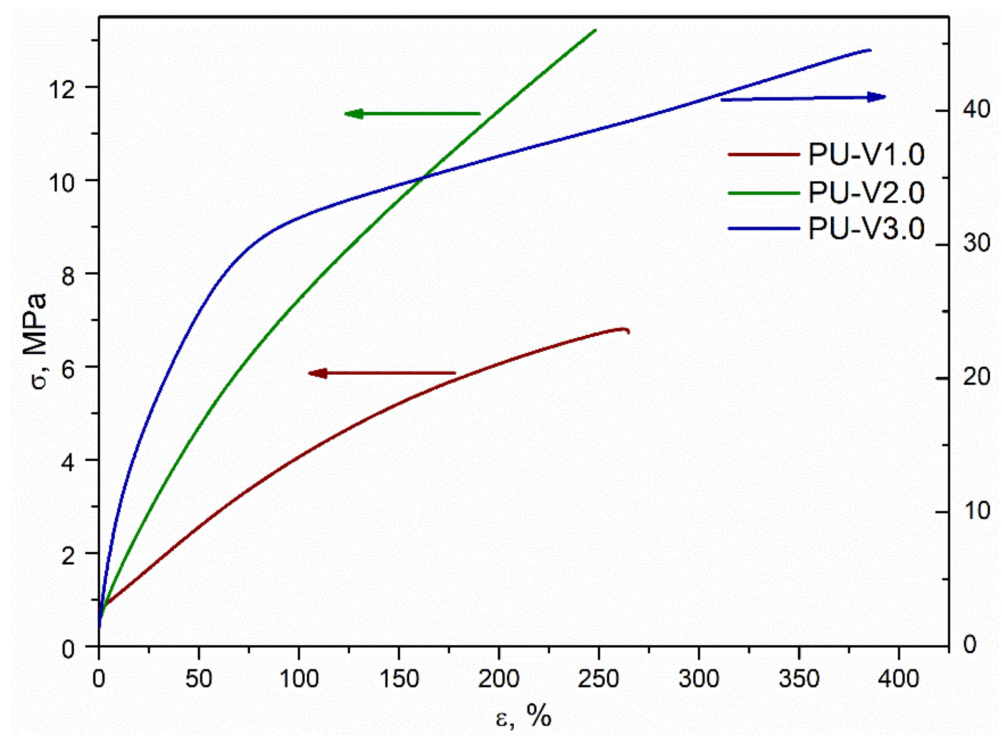

Figure 7. Representative loading diagrams for samples with different BMI content PU-V1.0-3.0: 1-PU-V1.0; 2-PU-V2.0; 3-PU-V3.0 (right scale for PU-V1.0-2.0, left scale for PU-V3.0).

We used a dissolution method for the crosslinked PUs reprocessing. Pristine films were cut using hand press to dumbbell-shaped samples for tensile strength tests. After the mechanical experiment, disrupted specimens were cut to even a smaller piece, decrosslinked, dissolved in DMF at $100^{\circ} \mathrm{C}$, cast in PTFE mold, and cured for $48 \mathrm{~h}$ at $60{ }^{\circ} \mathrm{C}$ (Figure 8). The same cycle was repeated five times for PU-V1.0-3.0. The stress at break $\sigma_{t}$, the elastic modulus $E$, and the elongation $\varepsilon$ corresponding to $\sigma_{t}$ were calculated from the obtained diagram for virgin samples and four recycles are presented in Figures 9-11.

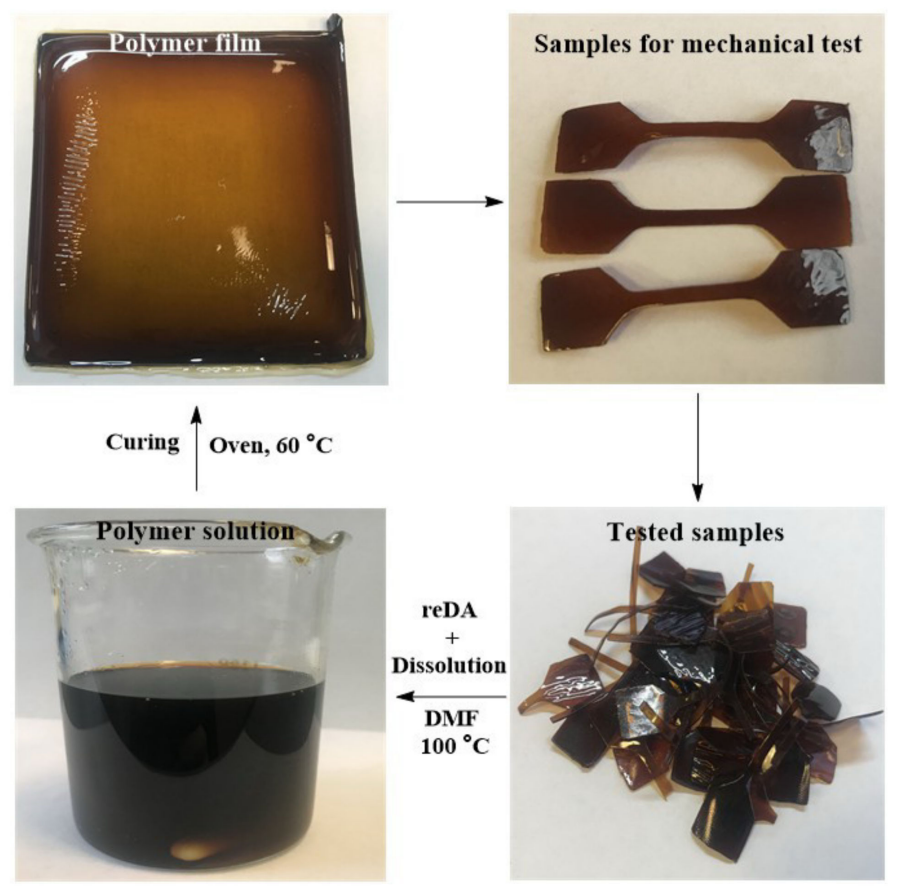

Figure 8. Thermal recyclability of PU-V1.0-3.0 by solution method. 


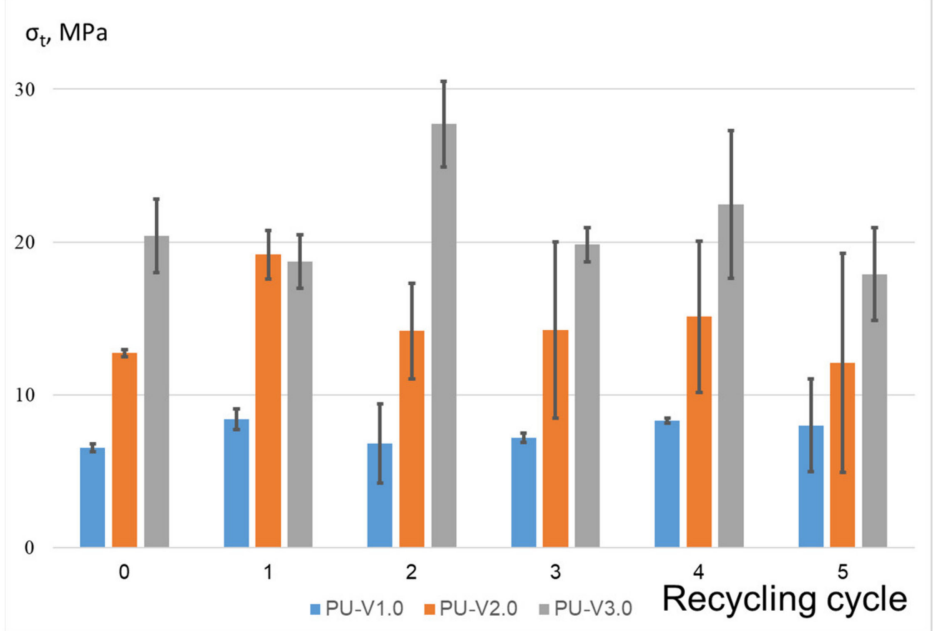

Figure 9. Stress at the break for PU-V1.0-3.0 after each reprocessing cycle.

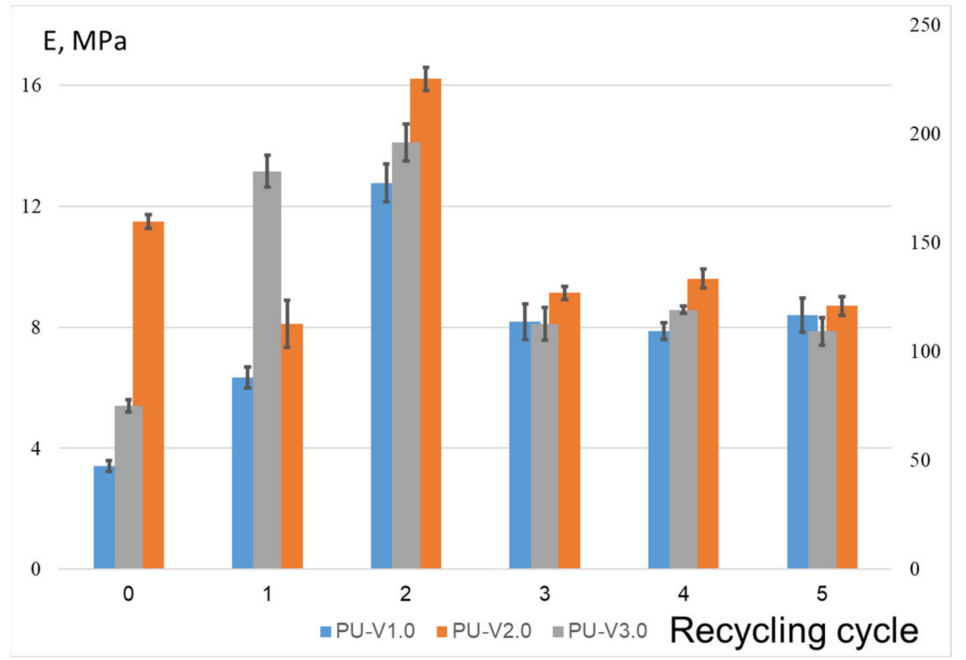

Figure 10. Elastic modulus for PU-V1.0-3.0 after each reprocessing cycle (left scale for PU-V1.0-2.0, right scale for PU-V3.0).

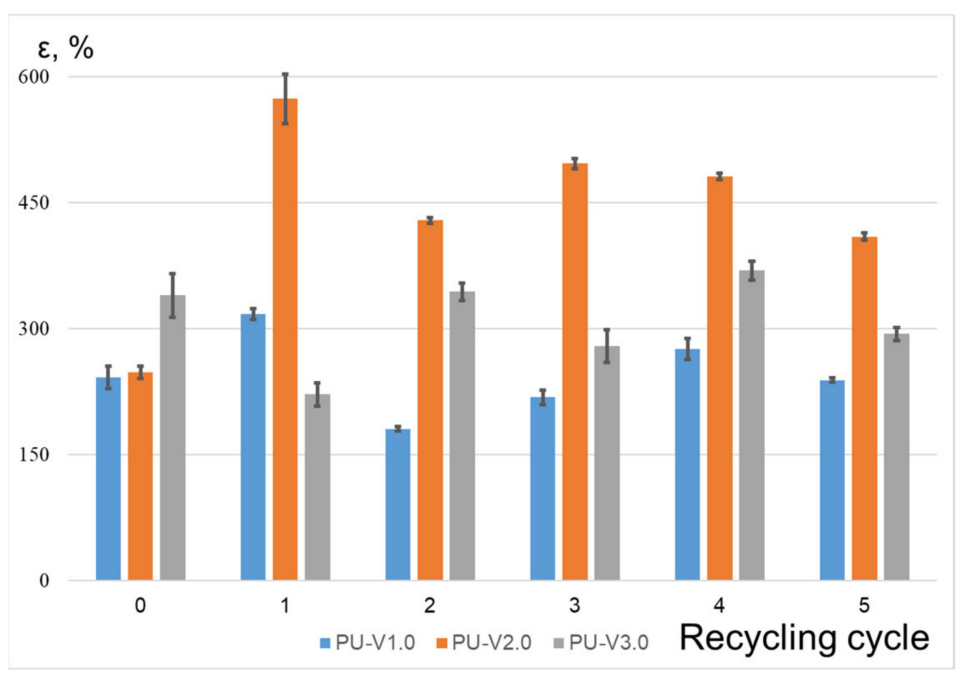

Figure 11. Elongation at the break for PU-V1.0-3.0 after each reprocessing cycle. 
The strength did not change significantly from the number of reprocessing cycles for PU-V1.0 and PU-V2.0 specimens (Figure 9). The tensile strength fluctuated around $8 \mathrm{MPa}$ for the polymer composition PU-V1.0 and $15 \mathrm{MPa}$ for PU-V2.0. In the case of the PU-V3.0, we observed a $50 \%$ increase in stress at the break after the first processing. With further processing cycles, the strength of the polyurethane decreased to the original and ceased to depend on the number of processing. The tensile strength, in this case, was about $20 \mathrm{MPa}$.

For all prepolymer/BMI ratios, the elastic modulus has a maximum at the second processing cycle (Figure 10). Moreover, for PU-V1.2 and PU-V2.2, the module almost doubles compared to the initial values. For PU-V3.2, the maximum during the second processing is less pronounced: the increase in the value of $\mathrm{E}$ is comparable with the spread of data. In subsequent processing, the elastic moduli for all compositions return to the level of the original compositions. As noted earlier, the higher the prepolymer/BMI ratio, the higher the elastic modulus. For compositions PU-V1.0-5 and PU-V2.0-5, moduli of elasticity are comparable and differ by no more than $30 \%$. For PU-V3.0-5, the elastic modulus is an order of magnitude higher than for the other two.

In contrast to the tensile strength and elastic modulus, the ultimate elongations of the compositions under tension are nearly independent of the number of processing steps (Figure 11). The level of ultimate elongation depends on the prepolymer/BMI ratio. The elongation at the break fluctuated around $200 \%, 450 \%$, and $300 \%$ for PU-V1.0-1.5, PU-V2.02.5, and PU-V3.0-3.5, respectively.

The PU-V1.0-3.0 mechanical properties strongly depend on BMI content. Yong modulus values increased from 13 to $196 \mathrm{MPa}$ (for linear PPG2000-based counterparts from 40 to $98 \mathrm{MPa}$ ). Thus, slightly crosslinked branched PUs had more elastic character than linear ones, and at some point, with the growing amount of DA-links, the material became much tougher. Tensile strength values for PU-V1.0-3.0 also show a tendency to grow with BMI content increased (linear materials showed the reverse trend $-\sigma_{t}$ decreased from $26 \mathrm{MPa}$ for the lowest BMI content to $13 \mathrm{MPa}$ for the highest one).

The morphology of PU-V1.0 and PU-V2.0 was analyzed by transmission electron microscopy. Morphological examination PU-V2.0 samples showed an amorphous phase typical for polyurethanes (Figure 12). Basic units are globules that generate domain structures in particular zones.

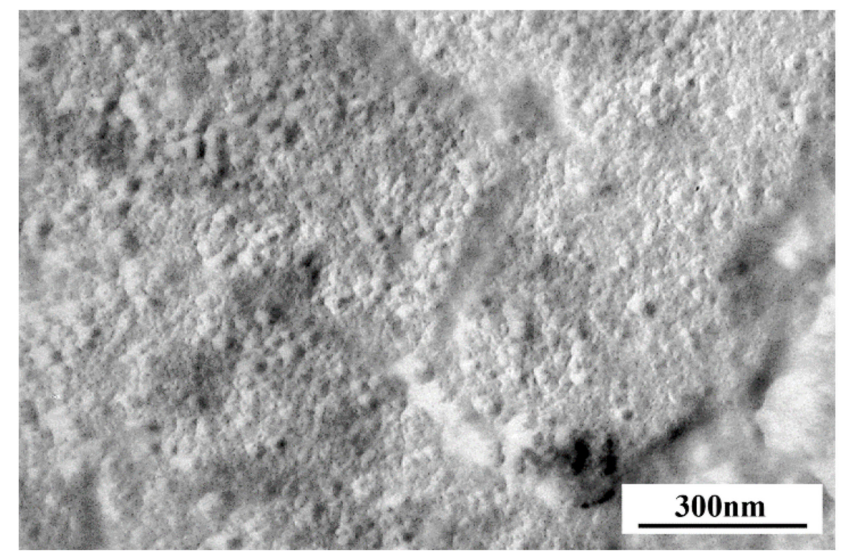

(a)

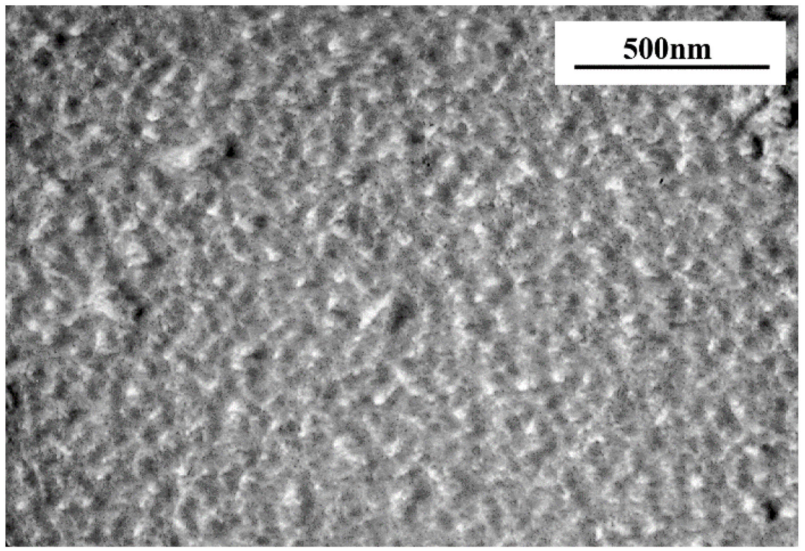

(b)

Figure 12. TEM images of PU-V1.0 (a) and PU-V2.0 (b).

The structural element size distribution (Figure 13) has a bimodal character (especially noticeable in PU-V1.0 sample) due to the difference in polyurethane blocks molecular mass. Domain structures formed from several globules and are not exceeding $300 \mathrm{~nm}$.

The PU-V1.0, and PU-V2.0 samples do not show significant structural differences affected by crosslinks density variation. Certain globules' size growth is caused by Voranol segments swelling in bismaleimide. 


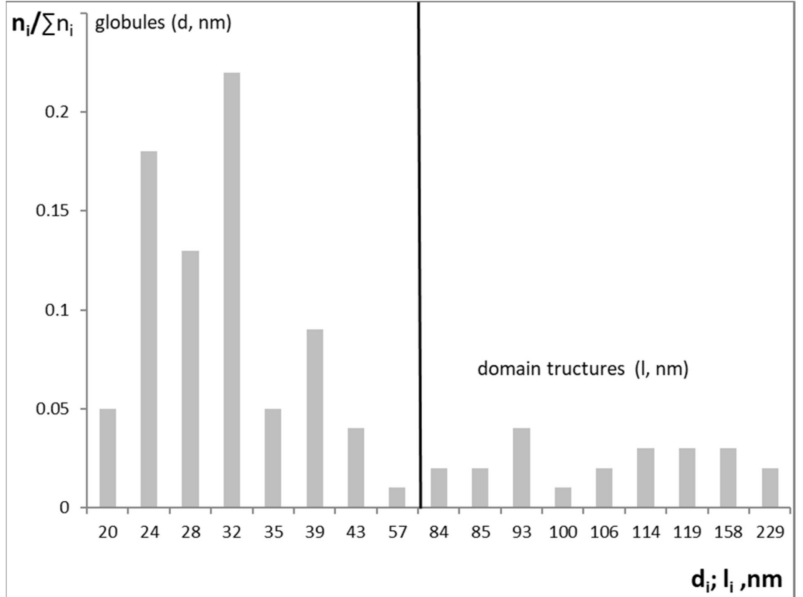

(a)

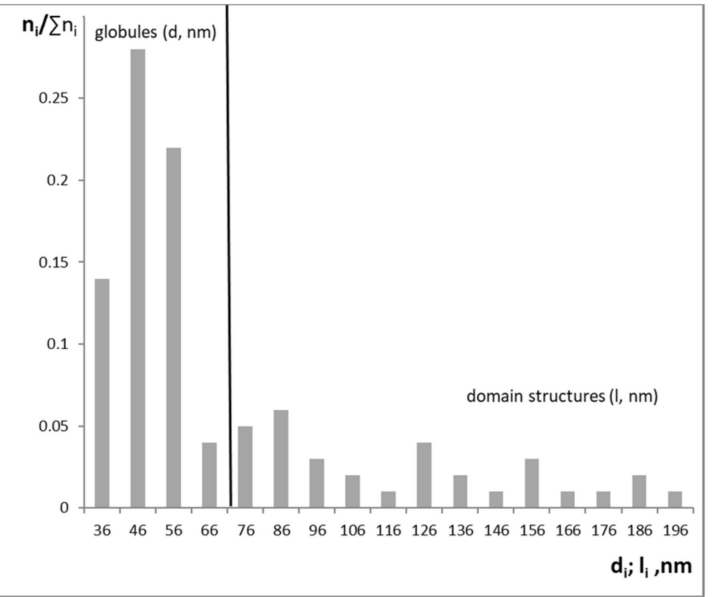

(b)

Figure 13. Globules and domains size distribution for PU-V1.0 (a) and PU-V2.0 (b).

\section{Conclusions}

We designed a new polyurethane-like material that is efficiently recyclable for up to five cycles without loss of strength and heat resistance, based on the reversible dynamic interaction between furan and maleimide. We used furan-rich difurfurylamine to increase the crosslinking density and hence the mechanical properties of the material. We investigated the thermal, mechanical properties, and morphology of materials obtained. We showed that Young modulus strongly depends on BMI content (from 8 to $250 \mathrm{MPa}$ ) that allows us to obtain materials of different elasticity as simple as varying BMI content. The reversibility of DA reaction between furan and maleimide components of the material was investigated by NMR spectroscopy, differential scanning calorimetry, and recycle testing. We showed that the stiffness of a material is strictly dependent on the amount of crosslinking agent. Interestingly, stress at the break values and Young modulus has a maximum for all three compositions after the first recycling test, which could be explained by the incompletion of DA-reaction between furane-functionalized prepolymer and maleimide crosslinker in pristine samples.

Supplementary Materials: The following are available online at https://www.mdpi.com/article/ 10.3390/polym13121935/s1, Figure S1: ${ }^{1} \mathrm{H}$ NMR spectrum of PU-V0 in DMSO-d6; Figure S2: ${ }^{13} \mathrm{C}$ NMR spectrum of PU-V0 in DMSO-d ${ }_{6}$; Figure S3: ${ }^{1} \mathrm{H}$ NMR spectrum of PU-V1.0 in DMSO-d6; Figure S4: ${ }^{13} \mathrm{C}$ NMR spectrum of PU-V1.0 in DMSO-d6; Figure S5: ${ }^{1} \mathrm{H}$ NMR spectrum of PU-V2.0 in DMSO-d $\mathrm{d}_{6}$; Figure S6: ${ }^{13} \mathrm{C}$ NMR spectrum of PU-V2.0 in DMSO-d $\mathrm{d}_{6}$; Figure S7: ${ }^{1} \mathrm{H}$ NMR spectrum of PU-V3.0 in DMSO-d6; Figure S8: ${ }^{13} \mathrm{C}$ NMR spectrum of PU-V3.0 in DMSO-d6; Figure S9: DSC curves for PU-V1.0 at $5 \mathrm{~K} / \mathrm{min}$; Figure S10: DSC curves for PU-V2.0 at $5 \mathrm{~K} / \mathrm{min}$; Figure S11: DSC curves for PU-V3.0 at $5 \mathrm{~K} / \mathrm{min}$; Figure S12: Shape of tensile strength samples of PU-L1.X-3.X $(X=0-5)$; Figure S13: Loading diagrams for samples PU-V1.1-3.1; Figure S14: Loading diagrams for samples PU-V1.2-3.2; Figure S15: Loading diagrams for samples PU-V1.3-3.3; Figure S16: Loading diagrams for samples PU-V1.4-3.4; Figure S17: Loading diagrams for samples PU-V1.5-3.5; Table S1: Tensile strength test parameters.

Author Contributions: E.P. and A.P. (Alexander Polezhaev)—design of the experiments; E.P. and I.C.—synthesis; A.P. (Alexander Pavlov)—NMR investigations and data analysis; E.A.—TMA experiment and data analysis; A.S.-TEM investigations and data analysis; V.S. - mechanical tests; E.P., A.P. (Alexander Polezhaev), and I.C.- data analysis; and E.P., A.P. (Alexander Polezhaev), and I.C. wrote the paper. All authors have read and agreed to the published version of the manuscript.

Funding: This research was funded by Russian Science Foundation, grant number 21-73-20117.

Institutional Review Board Statement: Not applicable.

Informed Consent Statement: Not applicable. 
Data Availability Statement: The data presented in this study are available on request from the corresponding author.

Acknowledgments: All monomers and polymers were characterized with the support of the Ministry of Science and higher education of the Russian Federation using scientific equipment Center for the Study of Molecular Structure of INEOS RAS (NMR Spectroscopy). Tensile strength tests were performed with the support of The Center of the National Technological Initiative (NTI) “Digital material science: new materials and substances" of Bauman Moscow State Technical University.

Conflicts of Interest: The authors declare no conflict of interest.

\section{References}

1. Akindoyo, J.O.; Beg, M.D.H.; Ghazali, S.; Islam, M.R.; Jeyaratnam, N.; Yuvaraj, A.R. Polyurethane types, synthesis and applications-A review. RSC Adv. 2016, 6, 114453-114482. [CrossRef]

2. Gama, N.V.; Ferreira, A.; Barros-Timmons, A. Polyurethane Foams: Past, Present, and Future. Materials 2018, 11, 1841. [CrossRef] [PubMed]

3. Saito, T.; Perkins, J.H.; Jackson, D.C.; Trammel, N.E.; Hunt, M.A.; Naskar, A.K. Development of lignin-based polyurethane thermoplastics. RSC Adv. 2013, 3, 21832-21840. [CrossRef]

4. Kumari, S.; Chauhan, G.S.; Monga, S.; Kaushik, A.; Ahn, J.-H. New lignin-based polyurethane foam for wastewater treatment. RSC Adv. 2016, 6, 77768-77776. [CrossRef]

5. Galbis, J.A.; García-Martín, M.G.; De Paz, M.V.; Galbis, E. Synthetic Polymers from Sugar-Based Monomers. Chem. Rev. 2016, 116, 1600-1636. [CrossRef]

6. Begines, B.F.; Zamora, I.; Roffé, M.; Mancera, J.A. Sugar-based hydrophilic polyurethanes and polyureas. J. Polym. Sci. Part A Polym. Chem. 2011, 49, 1953-1961. [CrossRef]

7. Schneiderman, D.K.; Vanderlaan, M.E.; Mannion, A.M.; Panthani, T.R.; Batiste, D.C.; Wang, J.Z.; Bates, F.S.; Macosko, C.W.; Hillmyer, M.A. Chemically Recyclable Biobased Polyurethanes. ACS Macro Lett. 2016, 5, 515-518. [CrossRef]

8. Shin, S.; Kim, H.; Liang, J.; Lee, S.; Lee, D. Sustainable rigid polyurethane foams based on recycled polyols from chemical recycling of waste polyurethane foams. J. Appl. Polym. Sci. 2019, 136, 47916. [CrossRef]

9. Howard, G.T. Biodegradation of polyurethane: A review. Int. Biodeterior. Biodegrad. 2002, 49, 245-252. [CrossRef]

10. Simón, D.; Borreguero, A.; de Lucas, A.; Rodríguez, J. Recycling of polyurethanes from laboratory to industry, a journey towards the sustainability. Waste Manag. 2018, 76, 147-171. [CrossRef]

11. Gu, L.; Wu, Q.-Y. Recyclable bio-based crosslinked polyurethanes with self-healing ability. J. Appl. Polym. Sci. 2018, 135, 46272. [CrossRef]

12. Zheng, K.; Tian, Y.; Fan, M.; Zhang, J.; Cheng, J. Recyclable, shape-memory, and self-healing soy oil-based polyurethane crosslinked by a thermoreversible Diels-Alder reaction. J. Appl. Polym. Sci. 2018, 135, 46049. [CrossRef]

13. Vlad, S.C.; Ciobanu, D.; Macocinschi, D.; Filip, D.; Spiridon, I. Evaluation of some polyetherurethane elastomers for chemicals, oils and solvents resistance. J. Optoelectron. Adv. Mater. 2009, 11, 1160-1168.

14. Li, K.; Wei, P.; Huang, J.; Xu, D.; Zhong, Y.; Hu, L.; Zhang, L.; Cai, J. Mechanically Strong Shape-Memory and Solvent-Resistant Double-Network Polyurethane/Nanoporous Cellulose Gel Nanocomposites. ACS Sustain. Chem. Eng. $2019,7,15974-15982$. [CrossRef]

15. Zhang, Y.J.; Liao, X.; Fang, F.; Bai, K.; Qiao, L.; Wang, L. Renewable High-Performance Polyurethane Bioplastics Derived from Lignin-Poly(E-caprolactone). ACS Sustain. Chem. Eng. 2017, 5, 4276-4284. [CrossRef]

16. Chattopadhyay, D.; Raju, K. Structural engineering of polyurethane coatings for high performance applications. Prog. Polym. Sci. 2007, 32, 352-418. [CrossRef]

17. Zhang, J.; Jiang, G.; Huang, T.; Yu, W.; Gao, Y. Synthesis and performance of polyurethane/silicon oxide nano-composite coatings. Sci. Eng. Compos. Mater. 2019, 26, 301-307. [CrossRef]

18. Fortman, D.J.; Sheppard, D.T.; Dichtel, W.R. Reprocessing Cross-Linked Polyurethanes by Catalyzing Carbamate Exchange. Macromolecules 2019, 52, 6330-6335. [CrossRef]

19. Bergman, S.D.; Wudl, F. Mendable polymers. J. Mater. Chem. 2007, 18, 41-62. [CrossRef]

20. Datta, J.M.; Włoch, M. Chapter 14-Recycling of Polyurethanes. In Polyurethane Polymers; Thomas, S.J., Datta, J., Haponiuk, J.T., Reghunadhan, A., Eds.; Elsevier: Amsterdam, The Netherlands, 2017; pp. 323-358.

21. Zia, K.M.; Bhatti, H.N.; Bhatti, I.A. Methods for polyurethane and polyurethane composites, recycling and recovery: A review. React. Funct. Polym. 2007, 67, 675-692. [CrossRef]

22. Fang, Y.; Du, X.; Jiang, Y.; Du, Z.; Pan, P.; Cheng, X.; Wang, H. Thermal-Driven Self-Healing and Recyclable Waterborne Polyurethane Films Based on Reversible Covalent Interaction. ACS Sustain. Chem. Eng. 2018, 6, 14490-14500. [CrossRef]

23. Chen, S.; Wang, F.; Peng, Y.; Chen, T.; Wu, Q.; Sun, P. A Single Molecular Diels-Alder Crosslinker for Achieving Recyclable Cross-Linked Polymers. Macromol. Rapid Commun. 2015, 36, 1687-1692. [CrossRef]

24. Zhang, Z.P.; Rong, M.Z.; Zhang, M.Q. Polymer engineering based on reversible covalent chemistry: A promising innovative pathway towards new materials and new functionalities. Prog. Polym. Sci. 2018, 80, 39-93. [CrossRef] 
25. Bessonov, I.V.; Polezhaev, A.V.; Kuznetsova, M.N.; Nelub, V.A.; Buyanov, I.A.; Chudnov, I.V.; Borodulin, A.S. Rheological and thermal analysis of low-viscosity epoxy-furan composites. Polym. Sci. Ser. D 2013, 6, 308-311. [CrossRef]

26. Bessonov, I.V.; Kopitsyna, M.N.; Polezhaev, A.V.; Nelyub, V.A. A mechanistic study of the reaction between furfural-acetone resins and polyamines. Polym. Sci. Ser. D 2016, 9, 17-21. [CrossRef]

27. Gandini, A.; Lacerda, T.M.; Carvalho, A.; Trovatti, E. Progress of Polymers from Renewable Resources: Furans, Vegetable Oils, and Polysaccharides. Chem. Rev. 2016, 116, 1637-1669. [CrossRef] [PubMed]

28. Liu, Y.-L.; Chuo, T.-W. Self-healing polymers based on thermally reversible Diels-Alder chemistry. Polym. Chem. 2013, 4, 2194-2205. [CrossRef]

29. Chen, X.; Dam, M.A.; Ono, K.; Mal, A.; Shen, H.; Nutt, S.R.; Sheran, K.; Wudl, F. A Thermally Remendable Cross-Linked Polymeric Material. Science 2002, 295, 1698-1702. [CrossRef] [PubMed]

30. Zhong, Y.; Wang, X.; Zheng, Z.; Du, P. Polyether-maleimide-based crosslinked self-healing polyurethane with Diels-Alder bonds. J. Appl. Polym. Sci. 2015, 132, 19. [CrossRef]

31. Platonova, E.O.; Vlasov, E.; Pavlov, A.A.; Kireynov, A.; Nelyub, V.A.; Polezhaev, A.V. Self-healing polyurethane based on a difuranic monomer from biorenewable source. J. Appl. Polym. Sci. 2019, 136, 47869. [CrossRef]

32. Zhang, C.; Madbouly, S.A.; Kessler, M. Biobased Polyurethanes Prepared from Different Vegetable Oils. ACS Appl. Mater. Interfaces 2015, 7, 1226-1233. [CrossRef]

33. Furtwengler, P.; Avérous, L. Renewable polyols for advanced polyurethane foams from diverse biomass resources. Polym. Chem. 2018, 9, 4258-4287. [CrossRef]

34. Khanderay, J.C.; Gite, V.V. Fully biobased polyester polyols derived from renewable resources toward preparation of polyurethane and their application for coatings. J. Appl. Polym. Sci. 2019, 136, 47558. [CrossRef]

35. Du, P.; Wu, M.; Liu, X.; Zheng, Z.; Wang, X.; Sun, P.; Joncheray, T.; Zhang, Y. Synthesis of linear polyurethane bearing pendant furan and cross-linked healable polyurethane containing Diels-Alder bonds. N. J. Chem. 2014, 38, 770-776. [CrossRef]

36. Du, P.; Jia, H.; Chen, Q.; Zheng, Z.; Wang, X.; Chen, D. Slightly crosslinked polyurethane with Diels-Alder adducts from trimethylolpropane. J. Appl. Polym. Sci. 2016, 133. [CrossRef]

37. Montano, V.; Wempe, M.M.B.; Does, S.M.H.; Bijleveld, J.C.; Van Der Zwaag, S.; Garcia, S.J. Controlling Healing and Toughness in Polyurethanes by Branch-Mediated Tube Dilation. Macromolecules 2019, 52, 8067-8078. [CrossRef]

38. Feng, L.; Yu, Z.; Bian, Y.; Lu, J.; Shi, X.; Chai, C. Self-healing behavior of polyurethanes based on dual actions of thermo-reversible Diels-Alder reaction and thermal movement of molecular chains. Polymer 2017, 124, 48-59. [CrossRef]

39. Pikhurov, D.V.; Zuev, V.V. Kinetics of formation of microstructure in polyurethane foams infused with micro and nanosized carbonaceous fillers. Polym. Eng. Sci. 2019, 59, 941-948. [CrossRef]

40. Höhne, C.-C.; Hanich, R.; Kroke, E. Intrinsic flame resistance of polyurethane flexible foams: Unexpectedly low flammability without any flame retardant. Fire Mater. 2018, 42, 394-402. [CrossRef]

41. Arshad, M.; Saied, S.; Ullah, A. PEG-lipid telechelics incorporating fatty acids from canola oil: Synthesis, characterization and solution self-assembly. RSC Adv. 2014, 4, 26439-26446. [CrossRef]

42. Szycher, M. Structure-Property Relations in Polyurethanes. In Handbook of Polyurethanes; Szycher, M., Ed.; CRC Press: Boca Raton, FL, USA, 2012; pp. 41-85.

43. Hunter, D.H.; Sim, S.K. 2,4-Diazapentadienes. I. Prototropy, Cyclization, and Addition-Elimination. Can. J. Chem. 1972, 50, 669-677. [CrossRef]

44. O'Platonova, E.; Vlasov, E.; Kireynov, A.; Polezhaev, A.V. Synthesis of cross-linked polyurethane with self-healing properties. Mater. Sci. Eng. 2019, 683, 012001. [CrossRef]

45. Tan, C.; Tirri, T.; Wilen, C.E. Investigation on the Influence of Chain Extenders on the Performance of One-Component MoistureCurable Polyurethane Adhesives. Polymers 2017, 9, 184. [CrossRef]

46. Goussé, C.; Gandini, A.; Hodge, P. Application of the Diels-Alder Reaction to Polymers Bearing Furan Moieties. 2. DielsAlder and Retro-Diels-Alder Reactions Involving Furan Rings in Some Styrene Copolymers. Macromolecules 1998, 31 , $314-321$. [CrossRef]

47. Petrova, T.V.; Solodilov, V.I.; Kabantseva, E.V.; Karelina, N.V.; Polezhaev, A.V. Furfurylglycidyl ether: A new effective active diluent for epoxy resins from bio-renewable raw materials. Mater. Sci. Eng. 2019, 683, 012070. [CrossRef]

48. Du, P.; Liu, X.; Zheng, Z.; Wang, X.; Joncheray, T.; Zhang, Y. Synthesis and characterization of linear self-healing polyurethane based on thermally reversible Diels-Alder reaction. RSC Adv. 2013, 3, 15475-15482. [CrossRef]

49. Froidevaux, V.; Borne, M.; Laborbe, E.; Auvergne, R.; Gandini, A.; Boutevin, B. Study of the Diels-Alder and retro-Diels-Alder reaction between furan derivatives and maleimide for the creation of new materials. RSC Adv. 2015, 5, 37742-37754. [CrossRef]

50. Cuvellier, A.; Verhelle, R.; Brancart, J.; Vanderborght, B.; Van Assche, G.; Rahier, H. The influence of stereochemistry on the reactivity of the Diels-Alder cycloaddition and the implications for reversible network polymerization. Polym. Chem. 2018, 10, 473-485. [CrossRef]

51. Yu, S.; Zhang, R.; Wu, Q.; Chen, T.; Sun, P. Bio-Inspired High-Performance and Recyclable Cross-Linked Polymers. Adv. Mater. 2013, 25, 4912-4917. [CrossRef] [PubMed] 